\title{
A possible new dawn for contraception
}

Modern contraception began in the 1960s with the introduction of combined oestrogen and progestogen (COC) pills and intrauterine devices made of thermoplastic. By the end of that decade, it had become apparent that COCs containing over $50 \mu \mathrm{g}$ of mestranol or ethinyl-estradiol carried a risk of producing venous thrombosis and thromboembolism. ${ }^{[1]}$ In the following years, the role of the 19-nortestosterone-derived progestins in the production of arteriovascular problems in COC users became apparent; this was particularly true of women who were older, smoked and were predisposed to cardiovascular disease, and was assumed to be due to the relative androgenicity of the first- and second-generation estrane and gonane progestins and their impact on lipids and other metabolic parameters.

The third- and fourth-generation progestins were anti-androgenic and it was hoped that they would produce less arteriovascular impact; unfortunately, they produced venous thromboembolism (VTE) at a rate marginally higher than that associated with the second-generation progestins. ${ }^{[2]}$ Newer preparations have emerged which contain natural estradiol $\left(\mathrm{E}_{2}\right)$ and nor-progesterones. The cardiovascular impact of these preparations is not yet fully quantified. However, it is the development of the most recently discovered estrogen, estetrol $\left(\mathrm{E}_{4}\right)$ and the exploitation of drospirenone (DRSP), the spironolactone-derived fourth-generation progestin, which has ushered in a new age in oral contraception.

Estetrol is produced in the fetal liver from 9 weeks of pregnancy. It was discovered by the Hungarian biochemist Egon Diczfalusy at the Karolinska Institute in Stockholm in 1965. ${ }^{[3]}$ It binds to the cell membrane receptor sites as do the other natural estrogens but has a different action on nuclear transcription, depending on the target cell. Unlike other estrogens, it inhibits endometrial and breast duct cells and similarly stimulates bone and vascular cells. It is excreted unchanged by the liver and has no effect on lipid metabolism and clotting factors. DRSP has some aldosterone antagonising properties and is therefore an inhibitor of the renin-angiotensin-aldosterone system. It is also anti-androgenic. A dose of $4 \mathrm{mg}$ of DRSP inhibits luteinising hormone (LH) and ovulation but allows folliclestimulating hormone (FSH) to produce endometrial proliferation and thus shedding and bleeding on withdrawal.

DRSP $4 \mathrm{mg}$ tablets (Slinda, Slynd (Exeltis Pharmaceuticals) are available in the USA and Europe packaged in a 24/4 configuration with 24 active and 4 non-active tablets. ${ }^{[4]}$ They are therefore the first progestin-only pills (POPs) which are taken like COCs in a regime which includes both active and non-active or placebo pills. ${ }^{[4]}$ A study of 20000 cycles showed that, like other POPs, they were not associated with venous thromboembolism (VTE), stroke or myocardial infarction and, unlike other POPs, had a pregnancy rate of 0.7 per 100 woman-years of use, i.e. a Pearl index (PI) of 0.7 and a bleeding profile which approaches that of COCs rather than POPs. Nevertheless, by cycle, from $13 \%$ up to $50 \%$ of users experienced some unscheduled bleeding beyond the week in which the nonactive tablets were taken. The study included adolescents, breastfeeding women, and enforced missed pill windows of 24 hours to mimic missed pill taking. DRSP $4 \mathrm{mg}$ appears to have the safety benefits of POPs with the convenience of COCs. There were no changes in serum glucose, lipids or haematological parameters. Two users developed hyperkalaemia. There were no significant changes in blood pressure during the course of the study but the tendency was for a marginal reduction in blood pressure. Slinda should be used with caution in women who have a tendency to hyperkalaemia owing to renal insufficiency or are using potassium-sparing medications. It is not known when Slinda will come to South Africa.

Regarding drosperinone and VTE, a full statement detailing risk and suggesting support of continued use of drosperinone-containing contraceptives was made by the American College of Obstetricians and Gynecologists in 2012, reaffirmed in 2018. ${ }^{[5]}$

Estetrol $15 \mathrm{mg} / \mathrm{DRSP} 3 \mathrm{mg}$ (Estelle (Mithra Pharmaceuticals)) is a COC which is also packaged as a $24 / 4$ presentation. Estetrol has been described by the company as the first native estrogen with selective action in tissues (NEST). Earlier studies showed $\mathrm{E}_{4}$ to be better tolerated when combined with DRSP rather than levonorgestrel (LNG) ${ }^{[6]}$ There were also no significant changes from baseline in serum glucose, lipids or haematological indices when compared with the second-generation progestin combinations with LNG and more favourable compared with ethinyl-estradiol/ DRSP formulations. ${ }^{[7]}$ The results of a large multicentre open-label phase 3 trial in Europe and the USA/Canada of this combination (4 FREEDOM) were recently presented at the 13th Congress of the European Society of Gynecology in Vienna by Prof. M Creinin from Sacramento, California. An analysis of over 40000 cycles which included women aged 16 - 35 including $5 \%$ with a BMI above 30 was presented. The primary endpoint was the PI which was 0.44 in the European arm and 2.65 in the North American one. ${ }^{[8]}$ This differential is typical in worldwide contraceptive trials for various reasons. Cycle control was very good, with only $16 \%$ of women reporting intracyclic bleeding which was considered to be bleeding beyond day 24 and the 7 following days, i.e. including the first 3 days of active tablets of the next cycle, which was considered to be the 'bleeding window'. Lack of any withdrawal bleed was found in $7.9 \%$ of users. Nevertheless, $6 \%$ of the subjects discontinued because of bleeding irregularities. Acne and headache accounted for another $6 \%$ of withdrawals. There was no association with VTE, stroke or myocardial infarction but true confirmation will only really come from future epidemiological studies. Estelle is expected to become available in Europe and North America early next year. It is not known when it will become available in South Africa.

The dawn of hormonal contraception totally free of potential serious cardiovascular side-effects yet maintaining all the known health benefits of administering female reproductive hormones appears to have arrived; this time, it should not be a false one.

\section{Norman D Goldstuck}

Department of Obstetrics and Gynaecology, Faculty of Medicine and Health Sciences, University of Stellenbosch, Cape Town, South Africa nahumzh@yahoo.com

1. Inman WH, VesseyMP, Westerholm B, Engelund A. Thromboembolic disease and the steroidal content of oral contraceptives. A report to the Committee on Safety of Drugs. Br Med J 1970;2:203-209.

2. Lidegaard O, Nielsen LH, Skovlund CW, Skjeldestad FE, Lokkegaard E. Risk of venous thromboembolism from use of oral contraceptives containing different progestogens and oestrogen doses: Danish cohort study, 2001-9. BMJ 2011;343:d6423. https://doi.org/10.1136/bmj.d6423

3. Schwers J, Eriksson G, Wiqvist N, Diczfalusy E. 15a-hydroxylation: A new pathway of estrogen metabolism in the human fetus and newborn. Biochim Biophys Acta 1965;100:313-316. 


\section{EDITORIAL}

4. Duijkers IJM, Heger-Mahn D, Drouin D, et al. Maintenance of ovulation inhibition with a new progestogen-only pill containing drospirenone after scheduled 24-h delays in pill intake. Contraception 2016;93:303-309.

5. American College of Obstetricians and Gynecologists. Risk of venous thromboembolism amon users of drospirenone-containing oral contraceptive pills. Committee Opinion No. 540.

6. Apter D, Zimmerman Y, Beekman L, et al. Estetrol combined with drospirenone: An oral contraceptive with high acceptability, user satisfaction, well-being and favourable body weight control. Eur J Contracept Reprod Health Care 2017;4:260-267. https://doi.org/10.1080/1362518 7.2017 .1336532
7. Creinin MD, Rosing J, Jost M, Kinet V, Chatel G, Foidart, Jean M. Estetrol combined with drospirenone: A new oral contraceptive with a favorable hemostatic profile [20OP]. Obstet Gynecol 2019;133:7. https://doi.org/10.1097/01.AOG.0000559087.93476.bc

8. Creinin MD. EVIDENCE: E4 FREEDOM Phase III study results: A new era in combined hormonal contraception. 13th Congress of the European Society of Gynecology 2019, 16-19 October, Vienna,

S Afr J Obstet Gynaecol 2019;25(3):70-71. https://doi.org/10.7196/SAJOG.2019.v25i3.1528 